habría otorgado a la fantasía un segundo papel de comprobación de las propuestas ahora formuladas por la cogitativa, llevando a cabo una revisión de su anterior realismo tan directo, mediante su comparación con la información recibida por el sentido común y por cada uno de los sentidos, en la medida que se establece entre ellos una relación de imagen y de similitud. En cualquier caso la reversio ad phantasmata se produce una vez que la información sensible ha sido recogida e interpretada en virtud de la fuerza de la cogitativa (vis cogitativa), contando ya con la ayuda del intelecto agente.

Para concluir una reflexión crítica. Lisska inicia su monografía resaltando el contexto naturalista de las propuestas del Aquinate, llevando a cabo un tránsito desde la ontología a la filosofía de la mente. Se trata de propuestas que han despertado un gran interés por parte de la neurociencia, desbordando las pretensiones filosóficas con que fueron formuladas. Algo similar ocurre con el concepto de intencionalidad, que se formuló desde unos presupuestos ontológicos muy precisos, aunque hoy día la filosofía de la mente ha terminado dándole un significado muy distinto. En este sentido lo que se concibió como un acto del ente ha pasado a ser considerado un simple objeto de un proceso mental, sin que el cambio pueda considerarse trivial. Se trata de una observación que, sin duda, señala la distancia existente entre las propuestas del Aquinate y el uso que actualmente se les pretende dar.

CARLOS ORTIZ DE LANDÁZURI Universidad de Navarra

\title{
SALVADOR H. MARTÍNEZ, Filosofía de Virgilio de Córdoba. Aristotélico-averroista del siglo XIII, Edición del texto latino y traducción castellana, introducción y notas. León, Universidad de León, 2016, 287 pp., ISBN: 9788497737586
}

H. Salvador Martínez, Doctor por la Universidad de Toronto (1972), es profesor emérito de la Universidad de Nueva York, habiendo ocupado la cátedra de Literatura Medieval y Renacentista desde 1976. Ha dedicado diversas monografías a personajes y acontecimientos medievales tan señalados como Alfonso X El Sabio (2016, 2003), Berenguela la Grande (2012), la rebelión de los Burgos (1992), o al «Poema de Almería» (1975), Por su parte, La filosofía de Virgilio de Córdoba, o Virgilio hispano, pretende desentrañar el enigma de un manuscrito medieval que habría sido redescubierto en el siglo XVIII por el copista D. Francisco Xavier de Palomares a partir de otro manuscrito en latín del siglo XIV conservado en la catedral de Toledo, cuya redacción no podría ser posterior a la muerte de Averroes en 1198. Sin embargo el manuscrito original latino anterior del siglo XIII, así como su correspondiente original en árabe no se había podido localizar. En cualquier caso Martínez pretende llevar a cabo una localización de su autor mediante una resolución de las dificultades interpretativas que presenta el análisis textual interno del manuscrito. De este modo se acaba atribuyendo la autoría de la Filosofía de Virgilio de Córdoba a un clérigo mozárabe goliárdico o itinerante del siglo XIII afincado en Toledo de orientación aristotélico-averroísta heterodoxa, amancebado y abanderado de la libertad sexual, adicto a la nigromancia o magia negra, que escribe en un latín muy vulgar y que presenta pocas o ninguna señal de saber árabe. Se pretende así retrotraer la presencia a nivel popular del averroísmo latino en España al siglo XIII, ejerciendo una fuerte influencia muy directa en las obras de los arciprestes de Hita y de Talavera, entre otros, así como en toda Europa.

Además, en este estudio también se señalan otras apropiaciones indebidas de la figura de Virgilio, el autor de la Eneida. Por ejemplo, la de Virgilio Maro Grammaticus, o el pseudo Virgilio de Toulouse del siglo VII, aunque ninguna de sus obras pudiera ser anterior al siglo XI. También se describen las pintorescas reacciones de Marcelino Menéndez Pelayo o de F. Delpech ante sus bernardinas disparatadas o su picardía nigromante, aunque situándolas en el siglo XIV. Sin embargo, a pesar de todo, Martínez cree encontrar en sus escritos una valiosa información sobre el estado del sistema educativo medieval del trivium y quadrivium, tanto en Toledo como en la Córdoba del siglo XIII. Se resalta así la importancia ahora otorgada por el 
pseudo Virgilio a la Nigromancia o Refulgencia concebida como una nueva versión de la Demonología o magia negra. Pero a su vez se contrapone a la Ars Notoria concebida como una auténtica sabiduría angélica, o simplemente revelada. Sin embargo, al final se desconfía de la Ars Notoria y se deposita toda la confianza en Nigromancia y en los poderes ocultos demoniacos cuya obtención al final sólo depende de nosotros mismos.

La estructura de la obra, a pesar de sus incoherencias, es clara. Según F. Delpech, se recurre a la estrategia de la caja china que introduce el marco narrativo de la disputatio escolástica en otro más amplio de la ficción mántica y espiritista. Por su parte, Martínez se retrotrae al esquema de las Flores de filosofia de 1290, o también del Ars notoria sive Flores aurei de 1225, atribuida a un pseudo Apolonío de Tirana, donde, respectivamente, 37 filósofos se reúnen alrededor de Séneca, o se describe la adquisición de la sabiduría por Salomón no directamente, sino mediante la entrega de un libro. En este contexto se describe cómo los doce sabios de Toledo reunidos con otros tantos provenientes de las más diversas regiones de España aceptan la condición puesta por Virgilio, profesor a la sazón de Nigromancia o Refulgencia, de reunirse en Córdoba, para resolver una serie de cuestiones espinosas. Se pasa a continuación a abordar los sucesivos temas espinosos debatidos, a saber: 1) Sobre la causa primera; 2) Sobre la eternidad del mundo; 3) Sobre el alma. 4) A continuación Virgilio resuelve todas las cuestiones, actuando más como un mago que recurre a los genios malignos que como un auténtico sabio; 5) Virgilio sintetiza todo su pensamiento en una retahíla interminable de proverbios y máximas muy antiescolásticos y heterodoxos; 6) Se recoge una breve relación de los centros de estudio existente en España, y se retrotrae a Salomón la génesis mítica del Arte notoria transmitida a Occidente a través de Aristóteles. 7) Se concluye con una recomendación de Virgilio a todos los españoles para que sean fieles a su filosofía.

Evidentemente la lectura averroísta de Aristóteles arraigó profundamente en la cultura popular española y también europea, como reconoce Alain de Libera. Martínez reconstruye una escuela catedralicia toledana que se habría movido alrededor de la Escuela de traductores de Toledo y del entorno aristocrático de la corte de Alfonso X, como habría ocurrido en el caso de Álvaro de Oviedo, Domingo Gundisalvus o Juan Hispano. Pero igualmente habría sucedido entre 1216 y 1236 en el ahora denominado círculo de filósofos leoneses. Al menos así lo refleja el De altera vita fideique controversis («La controversia sobre la otra vida y la fe») de Lucas de Tuy de 1236, o el Lucidario de 1293, mandado componer por Sancho IV y su esposa María de Molina, que sería el punto de partida de llamado molinismo, precisamente para combatir este tipo de herejías averroístas. A partir de aquí se habrían originado las grandes controversias europeas sobre el averroísmo latino, así como las sucesivas condenas, para culminar con la de Esteban Tempier en 1277. Sin embargo, según Martínez, estas condenas llegarían a España demasiado tarde, cuando ya el averroísmo estaría profundamente arraigado en la cultura popular.

Para concluir una reflexión crítica. Evidentemente la filosofia de Virgilio de Córdoba se encuentra enmarcada en una narración mítica que dibuja una Córdoba idílica donde se habría fomentado un saber «naturalista moderno», aunque distara mucho de lo que en realidad le estaba ocurriendo al propio Averroes. En cualquier caso, Toledo llegó a constituir un polo de atracción respecto del desarrollo de la nigromancia y de los saberes ocultos, como al menos ocurrió en los casos de Daniel de Morley, Alejandro Neckham y Alfredo Sareshel, como aquí se enfatiza. En este contexto la existencia de posteriores réplicas y contrarréplicas en León o en el conjunto de Castilla no tiene nada de extraño, sino que vienen a explicar el clima cultural que se había extendido rápidamente por toda Europa. Y en este contexto, no cabe duda que a «Virgilio de Córdoba» se le debería encuadrar en la historia de la filosofía como a uno de los más influyentes heterodoxos españoles.

CARLOS ORTIZ DE LANDÁZURI Universidad de Navarra 